CZASOPISMO INŻYNIERII LĄDOWEJ, ŚRODOWISKA I ARCHITEKTURY JOURNAL OF CIVIL ENGINEERING, ENVIRONMENT AND ARCHITECTURE

JCEEA, t. XXXIII, z. 63 (3/16), lipiec-wrzesień 2016, s. 391-398

Beata SADOWSKA ${ }^{1}$

\title{
EFEKTYWNY EKONOMICZNIE I EKOLOGICZNIE STANDARD ENERGETYCZNY BUDYNKÓW MIESZKALNYCH JEDNORODZINNYCH W WOJEWÓDZTWIE PODLASKIM
}

\begin{abstract}
W referacie przedstawiono wybrane aspekty projektowania i wznoszenia budynków o niskim zapotrzebowaniu na energię w województwie podlaskim na tle aktualnych wymagań ochrony cieplnej w Polsce. Przedstawiono uwarunkowania klimatyczne oraz inne czynniki, wpływające na energochłonność budynków obejmujące zarówno rozwiązania architektoniczne, materiałowe, jak i instalacyjne. Dla zaprojektowanych i rzeczywiście eksploatowanych jednorodzinnych budynków mieszkalnych, zlokalizowanych w północno-wschodniej Polsce, wyznaczono charakterystyki energetyczne i zbadano wpływ poszczególnych rozwiązań na bilans cieplny. Przeanalizowano zmiany wskaźników energetycznych przedmiotowych budynków przy usytuowaniu ich w różnych strefach klimatycznych Polski oraz wpływ ostrości klimatu na zużycie energii cieplnej podczas ich eksploatacji oceniając sytuację województwa podlaskiego na tle innych regionów Polski. Oszacowano wysokość nakładów inwestycyjnych związanych $\mathrm{z}$ zastosowanymi w budynkach rozwiązaniami poprawiającymi ich jakość energetyczną ponad minimalne wymagania techniczne i możliwe do osiągnięcia oszczędności finansowe w fazie eksploatacji budynków. Oceniono efektywność ekonomiczną podwyższania standardu energetycznego budynków mieszkalnych jednorodzinnych wzniesionych w województwie podlaskim względem budynków typowych, zaprojektowanych według aktualnie obowiązujących wymagań ochrony cieplnej. Dyskusji poddano również możliwości ograniczania emisji szkodliwych gazów i pyłów do atmosfery związanego z polepszaniem standardu energetycznego budynków mieszkalnych jednorodzinnych w świetle wybranych krajowych uregulowań dotyczących jej ograniczenia.
\end{abstract}

Słowa kluczowe: budynek niskoenergochłonny, uwarunkowania regionalne, efektywność ekonomiczna, niska emisja

\section{Wprowadzenie}

Wśród obszarów działań na rzecz ograniczenia i racjonalizacji zużycia energii znajduje się sektor budynków, będący jednym z jej największych konsumentów [1]. Rozwój rynku wyrobów budowlanych i instalacyjnych, w tym

\footnotetext{
${ }^{1}$ Beata Sadowska, Politechnika Białostocka, Zakład Podstaw Budownictwa i Fizyki Budowli, ul. Wiejska 45E, 15-351 Białystok; tel. 502200 249; b.sadowska@pb.edu.pl
} 
odnawialnych technologii energetycznych, sprawił iż wznoszenie budynków o obniżonych potrzebach cieplnych nie stanowi w obecnych czasach problemu technicznego. Nie zawsze jednak przesłanki polityczne czy środowiskowe idą w parze z efektywnością ekonomiczną. Zastosowanie technologii czy materiałów poprawiających jakość energetyczną budynku ponad minimalne wymagania techniczne wymaga poniesienia wyższych nakładów inwestycyjnych, które nie zawsze mają szansę być zrekompensowane przez niższe koszty ogrzewania budynku w czasie jego eksploatacji.

Aktualne wymagania ochrony cieplnej budynków w Polsce (WT2014) określone są w Rozporządzeniu w sprawie warunków technicznych, jakim powinny odpowiadać budynki i ich usytuowanie [2] (w artykule skrótowo oznaczanym jako WT). Rozporządzenie to podaje również wytyczne które będą obowiązywały od 1 stycznia 2017 r. (WT2017) oraz 2021 r. (WT2021) kiedy to wszystkie nowe budynki, zgodnie z dyrektywą 2010/31/UE [3], mają być budynkami o niemal zerowym zużyciu energii. W Polsce definicja tego typu budynków została podana, zgodnie z zapisami Ustawy o charakterystyce energetycznej [4], w Krajowym planie mającym na celu zwiększenie liczby budynków o niskim zużyciu energii [1]. Ustalono, że w warunkach krajowych budynek o niemal zerowym zużyciu energii będzie utożsamiany i określany jako budynek o niskim zużyciu energii i będzie spełniał wymogi WT2021. Wymogi te dotyczą izolacyjności cieplnej przegród oraz wyposażenia technicznego budynku, maksymalnej powierzchni okien o współczynniku przenikania ciepła nie mniejszym niż $0,9 \mathrm{~W} /\left(\mathrm{m}^{2} \cdot \mathrm{K}\right)$, a także wskaźnika nieodnawialnej energii pierwotnej $E P$ obliczonego według przepisów dotyczących metodologii obliczania charakterystyki energetycznej budynków. Wskaźnik ten wyraża jednostkowe roczne zapotrzebowanie na energię zawartą w kopalnych surowcach energetycznych, która nie została poddana procesowi konwersji lub transformacji [5]. Obejmuje on nie tylko efektywność energetyczną samego budynku, lecz również wykorzystywane w nim nośniki energii, stąd też nie nadaje się do oceny jego jakości energetycznej [6].

Na jakość energetyczną budynku, a co za tym idzie na zużycie energii, wpływ mają czynniki zarówno wewnętrzne, jak i zewnętrzne. Wiele zależy od lokalnych warunków klimatycznych, ale i od umiejętnego wykorzystania uwarunkowań urbanistycznych (usytuowanie budynku względem stron świata, wysokość i zacienienie od sąsiadującej zabudowy, otaczająca zieleń i położenie w terenie pozwalające zmniejszyć niekorzystne oddziaływanie wiatru i maksymalnie wykorzystać zyski od słońca, a także oświetlenie światłem naturalnym). Inne czynniki, które powinny być wzięte pod uwagę już na etapie projektowania budynku to:

- prawidłowo ukształtowana bryła budynku zapewniająca relatywną jej zwartość, a także odpowiednią organizację przestrzeni wewnętrznej poprzez właściwe rozplanowanie położenia pomieszczeń i stosowanie ich zblokowania,

- odpowiednio dobrane właściwości wyrobów budowlanych i rozwiązań konstrukcyjnych zastosowanych w obudowie budynku (opłacalna ekonomicznie grubość izolacji termicznej, poprawne rozwiązanie detali architektonicznych, 
minimalizujące wpływ mostków cieplnych, wyroby zapewniające wysoką szczelność na infiltrację powietrza, stolarka okienna i drzwiowa o niskich wartościach współczynnika przenikania ciepła, oszklone werandy przyległe do budynku, buforowe pomieszczenia nieogrzewane, przegrody akumulujące ciepło, czy specjalne elementy obudowy),

- technika instalacyjna na poziomie zapewniającym wysoką sprawność wytwarzania, magazynowania, dystrybucji i emisji ciepła w budynku oraz regulację pracy instalacji, a także ograniczenie zapotrzebowania na pomocniczą energię elektryczną związaną z działaniem instalacji w budynku; odzysk ciepła ze zużytego powietrza wentylacyjnego, wykorzystanie źródeł ciepła na biopaliwa, kogeneracji i źródeł energii odnawialnej (wiatrowej, geotermalnej i słonecznej pozyskiwanej bezpośrednio przez kolektory lub fotoogniwa bądź pośrednio pompami ciepła i w wymiennikach gruntowych).

W obecnych czasach ważna jest także dbałość o ograniczanie emisji szkodliwych gazów i pyłów do atmosfery. Polskie regulacje wdrażające postanowienia dyrektyw Unii Europejskiej w tej kwestii zawarte są m.in. w ustawie Prawo ochrony środowiska [7]. W artykule podjęto próbę określenia efektywnego ekonomicznie i ekologicznie standardu energetycznego budynków jednorodzinnych [8], zlokalizowanych w północno-wschodniej Polsce.

\section{Opis budynków niskoenergetycznych i ich charakterystyka energetyczna w różnych lokalizacjach w Polsce}

Do analizy wybrano dwa mieszkalne budynki jednorodzinne, zlokalizowane w województwie podlaskim (w Białymstoku lub jego okolicach).

Budynek B1 (o powierzchni $177,0 \mathrm{~m}^{2}$, parterowy z poddaszem użytkowym, o rzucie w kształcie zbliżonym do kwadratu) to energooszczędny budynek wzniesiony w 2000 roku, dla którego średni wskaźnik rocznego zapotrzebowania na energię końcową do ogrzewania $E K_{c o}$, odniesiony do warunków sezonu standardowego wynosi $52,1 \mathrm{kWh} /\left(\mathrm{m}^{2} \cdot\right.$ rok $)$. Ściany zewnętrzne budynku B1 trójwarstwowe (o $U=0,20 \mathrm{~W} / \mathrm{m}^{2} \cdot \mathrm{K}$ ) wykonano $\mathrm{z}$ cegły silikatowej, $\mathrm{z}$ warstwą wełny mineralnej gr. $18 \mathrm{~cm}$. W dachu zastosowano wełnę mineralną gr. $18 \mathrm{~cm}$ między krokwiami i dodatkowo $2 \mathrm{~cm}$ styropianu $\mathrm{w}$ ruszcie pod krokwiami i osiągnięto $U=0,18 \mathrm{~W} / \mathrm{m}^{2} \cdot \mathrm{K}$. W podłodze na gruncie zastosowano styropian gr. $10 \mathrm{~cm}$, zaś okna o $U_{w}=1,90 \mathrm{~W} / \mathrm{m}^{2} \cdot \mathrm{K}$.

Budynek B2 (o powierzchni $145,7 \mathrm{~m}^{2}$, parterowy, o rzucie w kształcie litery T) zaprojektowano w standardzie NF15 wg wymagań NFOŚiGW, w technologii tradycyjnej [9]. Ściany zewnętrzne przewidziano $\mathrm{z}$ betonu komórkowego $(\lambda=0,12 \mathrm{~W} / \mathrm{m} \cdot \mathrm{K}) \mathrm{z}$ warstwą styropianu gr. $30 \mathrm{~cm}$ i $\lambda=0,037 \mathrm{~W} / \mathrm{m} \cdot \mathrm{K}$ co pozwoliło osiągnąc $U=0,10 \mathrm{~W} / \mathrm{m}^{2} \cdot \mathrm{K}$. Stropodach wentylowany $\left(U=0,09 \mathrm{~W} / \mathrm{m}^{2} \cdot \mathrm{K}\right)$ posiada wełnę mineralną gr. $40 \mathrm{~cm} \mathrm{i} \lambda=0,035 \mathrm{~W} / \mathrm{m} \cdot \mathrm{K}$. W podłodze na gruncie termoizolacja ma gr. $35 \mathrm{~cm}$ (o $\lambda=0,031 \mathrm{~W} / \mathrm{m} \cdot \mathrm{K})$, wykonano również izolację termiczną obwodową. Zastosowano stolarkę okienną z profilami ramowymi o wy- 
sokich parametrach izolacyjności cieplnej, z ciepłymi zestawami szybowymi i ciepłymi ramkami, o wypadkowym współczynniku $U_{w}=0,74 \div 0,80 \mathrm{~W} /\left(\mathrm{m}^{2} \cdot \mathrm{K}\right)$.

Oba budynki są wyposażone w wentylację mechaniczną nawiewno - wywiewną z odzyskiem ciepła (o sprawnościach odpowiednio 93 i $55 \%$ ), zaś budynek B1 dodatkowo w gruntowy wymiennik ciepła do wstępnego podgrzewu powietrza wentylacyjnego. Jako źródło ciepła zastosowano kotły gazowe kondensacyjne (o sprawności wytwarzania równej $0,91 \mathrm{w}$ budynku B1 i 0,94 w budynku B2), sprawność instalacji c.o. to odpowiednio 0,85 i 0,90, zaś instalacji c.w.u. 0,58 .

Wyniki przeprowadzonych na podstawie $[5,10]$ obliczeń wskaźników energetycznych rocznego zapotrzebowania na: energię użytkową $(E U)$, końcową $(E K)$ i nieodnawialną energię pierwotną $(E P)$ zestawiono w tab. 1.

Tabela 1. Zapotrzebowanie energetyczne budynków B1 i B2

Table 1. Energy performance of the building B1 and B2

\begin{tabular}{|c|c|c|c|c|}
\hline \multirow{2}{*}{ Charakterystyka } & \multirow{2}{*}{ Budynek } & $E \boldsymbol{E}$ & $E K$ & EP \\
\hline & & \multicolumn{3}{|c|}{$\left[\mathrm{kWh} /\left(\mathrm{m}^{2} \cdot \mathrm{rok}\right)\right]$} \\
\hline \multicolumn{5}{|c|}{ Wentylacja mechaniczna nawiewno-wywiewna z odzyskiem ciepła, zyski 3,0 W/m² } \\
\hline \multirow{2}{*}{$\begin{array}{l}\text { Wskaźnik rocznego zapotrzebowania na } \\
\text { energię dla systemu ogrzewania (c.o.) }\end{array}$} & B1 & 43,3 & 60,1 & 74,6 \\
\hline & $\mathrm{B} 2$ & 14,9 & 22,0 & 32,6 \\
\hline \multirow{2}{*}{$\begin{array}{r}\text { Wskaźnik rocznego zapotrzebowania na } \\
\text { energię dla systemu przygotowania ciepłej } \\
\text { wody użytkowej (c.w.u.) }\end{array}$} & B1 & 24,1 & 41,9 & 46,6 \\
\hline & B2 & 24,1 & 41,9 & 46,6 \\
\hline \multirow{2}{*}{$\begin{array}{l}\text { Wskaźnik rocznego zapotrzebowania na } \\
\text { energię budynku (łącznie c.o. i c.w.u.) }\end{array}$} & B1 & 67,4 & 102 & 121,2 \\
\hline & B2 & 39,0 & 63,8 & 79,2 \\
\hline \multicolumn{5}{|c|}{ Wentylacja mechaniczna nawiewno-wywiewna z odzyskiem ciepła / wentylacja naturalna, zyski $6,8 \mathrm{~W} / \mathrm{m}^{2}$} \\
\hline \multirow{2}{*}{$\begin{array}{r}\text { Wskaźnik rocznego zapotrzebowania na } \\
\text { energię dla systemu ogrzewania (c.o.) }\end{array}$} & B1 & $28,3 / 41,3$ & $40,8 / 56,1$ & $53,3 / 67,3$ \\
\hline & $\mathrm{B} 2$ & $4,6 / 19,1$ & $9,9 / 25,5$ & $19,3 / 33,7$ \\
\hline \multirow{2}{*}{$\begin{array}{r}\text { Wskaźnik rocznego zapotrzebowania na } \\
\text { energię dla systemu przygotowania ciepłej } \\
\text { wody użytkowej (c.w.u.) }\end{array}$} & B1 & 24,1 & 41,9 & 46,6 \\
\hline & B2 & 24,1 & 41,9 & 46,6 \\
\hline \multirow{2}{*}{$\begin{array}{l}\text { Wskaźnik rocznego zapotrzebowania na } \\
\text { energię budynku (łącznie c.o. i c.w.u.) }\end{array}$} & $\mathrm{B} 1$ & $52,4 / 65,4$ & $82,7 / 98,0$ & $99,9 / 113,9$ \\
\hline & B2 & $28,7 / 43,2$ & $51,7 / 67,3$ & $65,9 / 80,3$ \\
\hline
\end{tabular}

Uzyskano znaczne rozbieżności przy przyjęciu zysków wewnętrznych na poziomie $3,0 \mathrm{~W} / \mathrm{m}^{2}$ wg wymagań NFOŚiGW dla budynków energooszczędnych i $6,8 \mathrm{~W} / \mathrm{m}^{2} \mathrm{wg}$ [5]. W przypadku budynku B1 zmiana tego jednego parametru spowodowała spadek wskaźnika $E U_{c o}$ o blisko $35 \%$, zaś w przypadku budynku B2 aż o 69\% więc czym budynek jest ,lepszy energetycznie” tym wpływ ten jest istotniejszy. Oba analizowane budynki (B1 i B2) przy zastosowaniu w nich wentylacji nawiewno-wywiewnej z odzyskiem ciepła spełniły aktualne wymaganie dotyczące wskaźnika $E P\left(E P_{\max }=120 \mathrm{kWh} /\left(\mathrm{m}^{2} \cdot\right.\right.$ rok $\left.)\right)$, pomimo nie wypełnienia przez stolarkę okienną budynku B1 wymagań szczegółowych dotyczących współczynników przenikania ciepła. Również w przypadku, gdyby w budynkach zastosowana była wentylacja grawitacyjna, oba budynki spełniłyby aktualne wymaganie dotyczące wskaźnika $E P$, jednakże byłby problem z zapewnieniem przez budynek energooszczędny (B1) wymagań które będą obowiązywać od 
1 stycznia $2017 \mathrm{wg}$ [2] $\left(E P_{\max }=95 \mathrm{kWh} /\left(\mathrm{m}^{2} \cdot\right.\right.$ rok $\left.)\right)$, zaś w przypadku wymagań które będą obowiązywać od 1 stycznia $2021 \mathrm{wg}$ [2] $\left(E P_{\max }=70 \mathrm{kWh} /\left(\mathrm{m}^{2} \cdot \mathrm{rok}\right)\right)$ oba budynki (B1 i B2) nie mogły by być zrealizowane.

W przypadku budynku energooszczędnego (B1) udział ciepłej wody w strukturze zapotrzebowania na poszczególne rodzaje energii $(E U, E K$ i $E P)$ wyznaczone wg obowiązujących przepisów [5] wyniósł odpowiednio 46, 51 i $47 \%$, zaś w przypadku budynku NF15 (B2) 84,81 i 71\%. Tak więc, aby spełnić wymagania WT2021 należy albo znacznie obniżyć wartości współczynników przenikania ciepła przegród (jak w budynku B2) i zastosować w nim wentylację mechaniczną z wysokosprawnym odzyskiem ciepła, albo wykorzystać OZE (szczególnie do podgrzewu c.w.u.) czy niekonwencjonalne źródła energii.

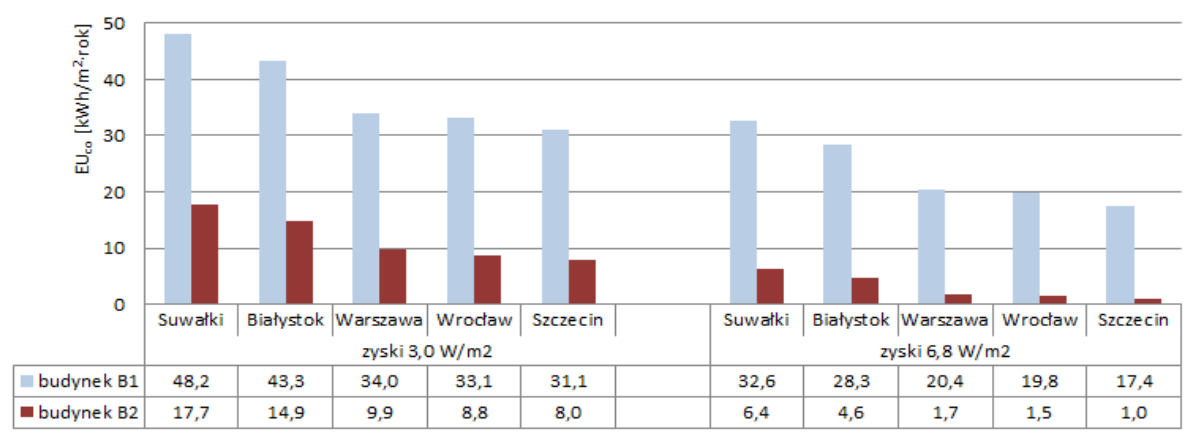

Rys. 1. Wpływ lokalizacji budynków na zapotrzebowanie na energię użytkową

Fig. 1. The effect of the location of buildings on demand for usable energy

Jak widać $\mathrm{z}$ rys. 1 zlokalizowanie analizowanych budynków w innej części województwa podlaskiego (Suwałki) powoduje wzrost wskaźnika $E U_{c o}$ o $11 \%$ (w przypadku budynku B1) i o $18 \%$ (w przypadku budynku B2) przy zyskach wewnętrznych na poziomie $3,0 \mathrm{~W} / \mathrm{m}^{2}$. Przy zyskach $\mathrm{wg}$ [5] wynoszących $6,8 \mathrm{~W} / \mathrm{m}^{2}$ (wielkość zdecydowanie zawyżona) wzrost ten jest jeszcze większy.

Budynek B1 położony w Suwałkach (przy zyskach 3,0 W/m²) ma zapotrzebowanie na energię użytkową o $55 \%$ większe niż taki sam zlokalizowany w Szczecinie, zaś w przypadku budynku B2 różnica ta sięga 120\% (rys. 1).

\section{Aspekty ekonomiczne i ekologiczne wzniesienia budynków niskoenergetycznych $w$ województwie podlaskim}

Wyznaczono zapotrzebowanie na energię, koszty ogrzewania i podgrzewu ciepłej wody oraz emisje $\mathrm{CO}_{2}$ budynku B2 w różnych wersjach jego wykonania (WT2014, WT 2017 i WT2021 z wentylacją naturalna oraz rzeczywisty B2 z wentylacją mechaniczną) przy zastosowaniu różnych źródeł ciepła (tab. 2) i czas zwrotu nakładów na polepszenie standardu energetycznego (rys. 2). W przypadku biomasy wyliczono rzeczywistą emisję $\mathrm{CO}_{2}$ oraz wyznaczoną wg [5]. 
Tabela 2. Porównanie efektywności poszczególnych wariantów

Table 2. Comparison of the effectiveness of the analysed variants

\begin{tabular}{|c|c|c|c|c|c|c|}
\hline \multirow{2}{*}{$\mathrm{Nr}$} & \multirow{2}{*}{$\begin{array}{c}\text { Wariant } \\
\text { (zyski 3,0 W/m2) }\end{array}$} & $E U_{c o}$ & EK & $E P$ & \multirow{2}{*}{$\begin{array}{c}\text { Koszt c.o. } \boldsymbol{i} \\
\text { c.w. } \\
\text { [PLN/rok] }\end{array}$} & \multirow{2}{*}{$\begin{array}{c}\Delta \boldsymbol{E}_{\mathrm{CO} 2} \\
{\left[\mathrm{Mg} \mathrm{CO}_{2} / \mathrm{rok}\right]}\end{array}$} \\
\hline & & \multicolumn{3}{|c|}{$\left[\mathrm{kWh} /\left(\mathrm{m}^{2} \cdot \mathrm{rok}\right)\right]$} & & \\
\hline 1 & WT2014 / gaz & \multirow{5}{*}{70,0} & 127,4 & 146,3 & 3863 & 4,03 \\
\hline 2 & WT2014 / gaz + kolektor & & 104,8 & 122,7 & 3375 & 3,41 \\
\hline 3 & WT2014 / gaz + kominek $(40 \%)$ & & 134,3 & 117,9 & 3098 & $5,37 / 3,06$ \\
\hline 4 & WT2014 / pompa ciepła & & 38,1 & 114,2 & 3327 & 4,62 \\
\hline 5 & WT2014 / biomasa & & 164,6 & 42,1 & 3811 & $5,12 / 0,40$ \\
\hline 6 & WT2017 / gaz & \multirow{5}{*}{60,3} & 116,0 & 133,8 & 3597 & 3,70 \\
\hline 7 & WT2017 / gaz + kolektor & & 93,4 & 110,1 & 3110 & 3,09 \\
\hline 8 & WT2017 / gaz + kominek (40\%) & & 121,9 & 109,2 & 2937 & $4,85 / 2,86$ \\
\hline 9 & WT2017 / pompa ciepła & & 34,8 & 104,5 & 3044 & 4,22 \\
\hline 10 & WT2017 / biomasa & & 149,2 & 39,0 & 3475 & $4,67 / 0,40$ \\
\hline 11 & WT2021 / gaz & \multirow{5}{*}{52,9} & 107,2 & 124,1 & 3462 & 3,44 \\
\hline 12 & WT2021 / gaz + kolektor & & 84,6 & 100,5 & 2974 & 2,76 \\
\hline 13 & WT2021 / gaz + kominek (40\%) & & 112,4 & 102,6 & 2815 & $4,45 / 2,71$ \\
\hline 14 & WT2021 / pompa ciepła & & 32,4 & 97,1 & 3044 & 3,93 \\
\hline 15 & WT2021 / biomasa & & 137,4 & 36,6 & 3218 & $4,32 / 0,40$ \\
\hline 16 & Rzeczywisty B2 / gaz & \multirow{5}{*}{14,9} & 63,8 & 79,2 & 2478 & 2,31 \\
\hline 17 & Rzeczywisty B2 / gaz + kolektor & & 41,3 & 55,6 & 1990 & 1,70 \\
\hline 18 & Rzeczywisty B2 / gaz + kom. (40\%) & & 65,4 & 73,2 & 2314 & $2,58 / 2,10$ \\
\hline 19 & Rzeczywisty B2 / pompa ciepła & & 21,7 & 65,1 & 1896 & 2,63 \\
\hline 20 & Rzeczywisty B2 / biomasa & & 78,6 & 29,0 & 2028 & $4,83 / 0,57$ \\
\hline
\end{tabular}

Nie we wszystkich $\mathrm{z}$ analizowanych wariantów udało się spełnić aktualne wymagania dotyczące wskaźnika $E P$ (nr 1, 2, 6 i 11), natomiast tylko w trzech $\mathrm{z}$ nich (17, 19 i 20) są spełnione wymagania które będą obowiązywać od 1 stycznia 2021 roku.

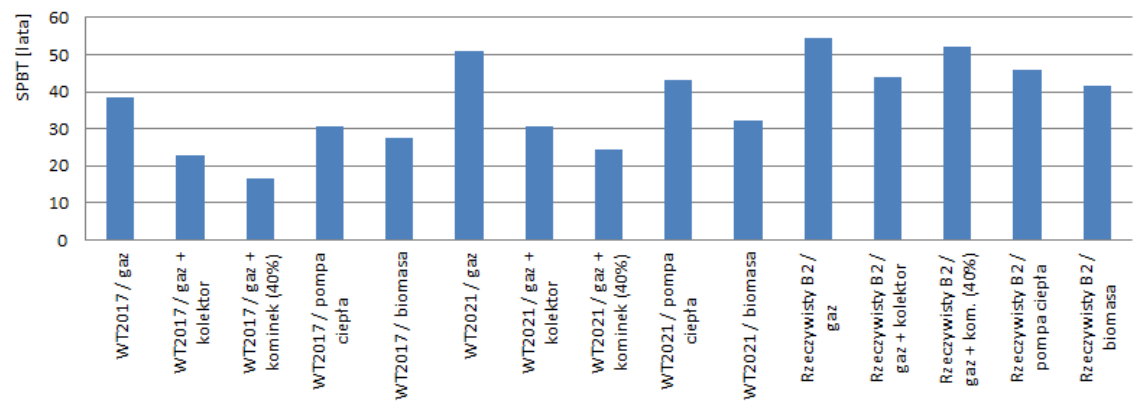

Rys. 2. Prosty czas zwrotu nakładów na polepszenie standardu energetycznego budynku B2

Fig. 2. Simply Pay Back Time to recoup investment costs of the improvement in energy standard of building $\mathrm{B} 2$ 


\section{Wnioski}

Lokalne warunki klimatyczne w sposób istotny wpływają na zużycie energii cieplnej. Budynki w województwie podlaskim, w zależności od ich jakości energetycznej, charakteryzują się wskaźnikami energetycznymi wyższymi nawet o $120 \%$ niż te same budynki zlokalizowane w innych rejonach Polski.

Wypełnienie wymagań szczegółowych określonych w WT nie gwarantuje spełnienia wymagania dotyczącego wskaźnika rocznego zapotrzebowania na energię pierwotną $E P$.

Osiągnięcie przez jednorodzinny budynek mieszkalny zlokalizowany w województwie podlaskim określonego w WT2021 wskaźnika EP jest możliwe przy znacznie obniżonych wartościach współczynników przenikania ciepła przegród (rzędu $0,10 \mathrm{~W} / \mathrm{m}^{2} \cdot \mathrm{K}$ ) i wentylacji mechanicznej z wysokosprawnym odzyskiem ciepła, albo przy wykorzystaniu alternatywnych źródeł energii.

Kolektor słoneczny pozwolił obniżyć EP o 16-30\% (jak również emisję $\mathrm{CO}_{2}$ ), pompa ciepła o $18-22 \%$ (przy wzroście emisji $\mathrm{CO}_{2}$ ), zaś biomasa znacznie obniżyła $E P$ o (nawet o ponad 70\%), jednak rzeczywista emisja $\mathrm{CO}_{2}$ jest wyższa niż w przypadku innych źródeł energii.

Prosty okres zwrotu nakładów na polepszenie jakości bryły budynku waha się od 38 do 55 lat, zaś przy wykorzystaniu OZE lub alternatywnych źródeł energii, pomimo ich znacznego kosztu inwestycyjnego jest niższy nawet o $36 \%$.

\section{Literatura}

[1] Krajowy Plan mający na celu zwiększenie liczby budynków o niskim zużyciu energii. Zał. do Uchwały Nr 91 Rady Ministrów z dnia 22 czerwca 2015 r. (poz. 614).

[2] Rozporządzenie Ministra Infrastruktury z dnia 5 lipca 2013 r. zmieniające rozporządzenie w sprawie warunków technicznych, jakim powinny odpowiadać budynki i ich usytuowanie (D.U. z dnia 13 sierpnia 2013 r. poz.926).

[3] Dyrektywa Parlamentu Europejskiego i Rady 2010/31/EU z dnia 19 maja 2010 r. w sprawie charakterystyki energetycznej budynków (D.U. UE z 18.6.2010, L153/13).

[4] Ustawa z dnia 29 sierpnia 2014 r. o charakterystyce energetycznej budynków (Dz. U. poz. 1200 , z późn. zm.).

[5] Rozporządzenie Min. Infrastruktury i Rozwoju z dnia 27 lutego 2015 r. w sprawie metodologii wyznaczania charakterystyki energetycznej budynku lub części budynku świadectw charakterystyki energetycznej (D.U. z dnia 18 marca 2015 r. poz.376).

[6] Sarosiek W., Sadowska B.: Jakość energetyczna budynków a wskaźniki zamieszczone w świadectwach, Materiały Budowlane 08/2010, s. 51-53.

[7] Ustawa z dnia 27 kwietnia 2001 r. Prawo ochrony środowiska (Dz.U. 2001 Nr 62 poz. 627 z późn. zm.).

[8] Sadowska B. „Model operacyjny projektowania energooszczędnych budynków mieszkalnych w zabudowie jednorodzinnej”, Rozprawa doktorska, Białystok 2010. 
[9] Weryfikacja projektu budynku jednorodzinnego w standardzie NF15, Narodowa Agencja Poszanowania Energii S.A., Białystok.

[10] PN-EN ISO 13790:2009 „Energetyczne właściwości użytkowe budynków. Obliczanie zużycia energii do ogrzewania i chłodzenia".

Badania zostały zrealizowane w ramach pracy $\mathrm{nr}$ S/WBiIŚ/3/2016 i sfinansowane ze środków na naukę MNiSW

\section{AN EFFECTIVE ECONOMICALLY AND ECOLOGICALLY ENERGY STANDARD OF DETACHED HOUSES IN PODLASKIE REGION}

\section{S u m m a r y}

In the paper are presented selected problems of design, construction and use of low energy housing situated in Podlaskie region in relation to current requirements and minimum performance for new buildings in Poland. The climatic conditions and other factors affecting the energy demand of the building including architectural and materials solutions as well as installation are listed. Author expressed the energy performance of two detached houses located in north-east Poland and examined the influence of individual solutions on the heat balance. The effect of the location of buildings in five climatic zones in Poland on energy indicators and the influence of climatic conditions on the energy use and consumption were analysed.

The investment costs result from applied in buildings solutions improving their energy quality above of minimum current requirements and financial savings of exploitation energy are calculated. There is presented economic efficiency of increasing of the energy standard of one-family detached houses in Podlasie voivodship in relation to typical buildings, designed according to current requirements. Additionally the study shows possibilities of reducing the emissions of harmful gases and dust into the atmosphere of related to improving of the energy standard of detached houses refer to chosen current legal status in Poland conducive to reducing emissions.

Keywords: low energy house, conditionings regional, economic efficiency, low emission

DOI:10.7862/rb.2016.222

Przestano do redakcji: $15.06 .2016 r$.

Przyjęto do druku: 30.11.2016 r. 